\title{
Are ready for market genetically modified, conventional and organic soybeans substantially equivalent as food and feed?
}

\author{
Bøhn, T. ${ }^{1,2}$, Cuhra, M. ${ }^{1,2}$, Traavik, T. ${ }^{1,2}$, Fagan, J. ${ }^{3}$ \\ ${ }^{1}$ GenØk - Centre for Biosafety, P.O. Box 6418, 9294 Tromsø, Norway \\ ${ }^{2}$ Faculty of Health Sciences, UiT The Arctic University of Norway, 9019 Tromsø, \\ Norway \\ ${ }^{3}$ Earth Open Source Institute, Suite \#2, 103 Full Moon Lane, Fairfield, Iowa 52556, \\ USA
}

Corresponding author: Thomas Bøhn, GenØk, Centre for Biosafety, P.O. Box 6418, 9294 Tromsø, Norway. Phone: +4777644541, Email: thomas.bohn@genok.no;

\section{Summary}

Important compositional elements, including residues of herbicides, were investigated in commercial soy varieties grown within the same geographical area. These included genetically modified, conventional and organic soybeans. Feed made from these soybeans was subsequently fed to the model organism Daphnia magna, while measuring the fitness performance (survival, growth and reproduction) during the full life cycle of the animals. The conventional and organic samples contained no residues of glyphosate or its degradation product AMPA, but the GM-soy contained such residues, averaging $9.0 \mathrm{mg} / \mathrm{kg}$. The fitness of $D$. magna fed organic soybeans was superior to that of animals fed GM soybeans, while animals fed conventional soybeans was intermediate. There were large fitness differences for $D$. magna fed raw soybeans, but smaller with heat-treated soy. In conclusion: herbicides associated with GM soybeans (and/or other factors associated with these crops) may compromise food and feed quality.

Keywords: Agricultural practice, GMO, herbicide residues, nutrition, food and feed quality, Daphnia magna, substantial equivalence 


\section{Introduction}

Quality of feed and food produced from agriculture is critically important for human and animal health, as it daily and continuously fuels and supports all processes essential to life in farmed animals and human consumers. Assessing the nutritional quality and safety of food and feedstuffs and the potential quality and safety differences among different food and feedstuffs is undoubtedly of very high priority, since every individual consumer organism, irrespective of health condition, age or gender, will be exposed persistently throughout life to basic components and potential contaminants of food and feed. The necessity of continuous safetyassessment is enhanced by the employment of numerous agrochemicals. As of today, about $85 \%$ of the genetically modified (GM) crop plants are herbicide tolerant (Beckie 2014) and are designed to be sprayed with herbicides during the growth season of the plant. Consequently, crops such as Roundup-ready soybean are accumulating herbicide residues in the final product (Bøhn et al. 2014). However, the maximum residue levels (MRLs), at present $40 \mathrm{mg} / \mathrm{kg}$ in the US and $20 \mathrm{mg} / \mathrm{kg}$ in the EU, make such accumulation legally accepted.

Long-term studies of food and feed products and agrochemicals are missing

The persistent food/feed exposure to food/feed stuff is not followed up with sufficient long-term feeding studies to assess potential effects. Thus, the sparse rodent feeding studies of new GM crop plants typically last for 90 days or less, covering only 10-15 $\%$ of the life span of the test-animals. Furthermore, monitoring programmes generally detect more than 7-8 different pesticides in surface waters and other environmental contexts, and multiple pesticides are routinely detected in foods and feedstuffs as well (EFSA 2014). In spite of that, current testing regimes for relevant agrochemicals are predominately based on acute exposure (short term) and specific testing of isolated single chemicals (Martin et al. 2003; Nørgaard and Cedergreen 2010) .

The lack of long-term feeding studies may be explained, at least in part, by high costs. The costs can be dramatically cut by using model organisms with shorter life-cycles than rodents. Daphnia magna (waterflea) is a good alternative. It performs a full lifecycle in 42 days. Daphnia is a sensitive sentinel species in freshwater ecosystems and is widely used as a model for ecotoxicological studies. Increasingly, Daphnia is used as a surrogate species to understand genomic responses to environmental stressors 
that are important factors in human health and well-being (NIH 2015).

Soy production is dominated by herbicide-tolerant (HT) Roundup Ready (RR) GM soy Globally, RR varieties of soy, maize, rapeseed and cotton are the predominant GM crops, and glyphosate is the most widely used herbicide globally with a production of 620000 tons in 2008 (Pollak 2011). Forecasts from Global Industry Analysts indicate that this figure will rise to 1.35 million metric tons worldwide by 2017, mainly driven by expansion of glyphosate-tolerant GM crop acreage. According to industry sources, the world soybean production in 2013 was 284 million metric tons, with the United States (32\%), Brazil (31\%), Argentina (19\%), China (4\%) and India (4\%) as the main producing countries (American Soy Association 2015). In 2014, soybeans were planted on about 34 million hectares in the USA, with Roundup Ready GM soy representing $94 \%$ of the production volume (USDA-NASS 2015). Also in the other leading producing countries, the RR GM soy dominates the market, accounting for 83 and $100 \%$ of the production in 2012, in Brazil and Argentina, respectively (American Soy Association 2013; USDA 2013). Globally, RR GM soybeans contributed to $79 \%$ of production in 2013 (James 2013).

\section{The Daphnia magna model}

The ecology and physiology of D. magna is understood in great detail. D. magna shares a large number of genes and core metabolic and regulatory pathways with the majority of organisms in the biosphere, including humans (Colbourne et al. 2011). Recent advances using $D$. magna include detailed molecular studies of the responsiveness to changing environmental conditions and to the toxic effects of chemicals at both the genomic and transcriptomic levels (Asselman et al. 2012; Orsini et al. 2011).

\section{Previous studies in D. magna}

D. magna has been used as an ecotoxicological model for testing GM crop plants in short-term studies (Mendelson et al. 2003; Raybould and Vlachos 2011) and over the full life-cycle (Bøhn et al. 2008), and for testing combinatorial effects of Bt toxins 
and predation risk (Bøhn et al. 2010). Cuhra and co-workers tested chronic effects of glyphosate and Roundup and showed that environmental concentrations of 0.05-0.45 mg/l (active ingredient) cause negative effects on D. magna offspring size and reproduction (Cuhra et al. 2013). Chemical residues of glyphosate and its primary metabolite, AMPA, are documented to be present in herbicide tolerant GM soy (Duke et al. 2003; Bøhn et al. 2014).

Given that (i) glyphosate and Roundup have been shown to cause negative effects in D. magna from environmental exposure at relatively low concentrations, i.e. below accepted US thresholds for surface waters $(0.7 \mathrm{mg} / \mathrm{l})$, and that (ii) glyphosate may accumulate in food and feed products, it is both interesting and important to test if, how, and at what concentration, residues of the same herbicides in plant material may cause negative health effects.

To investigate this further, we analyzed soybeans from a defined geographical region in the state of Iowa (representing real-life samples similar to what a consumer could expect to find in the market), produced under different agricultural practices (i.e. GM, conventional and organic), to assess nutritional content, elemental characteristics, and pesticide residues. Subsequently we compared fitness performance (survival, growth and reproduction) of D. magna that were fed meals made from GM, conventional or organic soybeans.

\section{Materials and Methods}

\section{Soy samples and characterization}

Three kg samples of whole soybeans were obtained from 31 sites in Iowa, USA. Seed type and farming history including pesticide use were noted for all samples. Samples were from 3 categories of agricultural practices: $n=11$ samples were from organic agriculture, $n=10$ samples were from "conventional agriculture”, and $n=10$ samples were from GM agriculture (all herbicide tolerant, "Roundup-Ready”, event 40-3-2). Organic farmers did not use herbicides or pesticides. Conventional and GM farmers used a range of agrochemicals in their soybean production.

For details on use of agrochemicals by the farmers, soybean varieties grown, analyses of nutritional contents in the soybean and methods for analyzing chemical residues, 
see (Bøhn et al. 2014).

\section{Feeding studies in D. magna}

The feeding experiment included 300 animals in total: 18 treatments with soy feed (15 animals per treatment) and a control group of 30 animals. The feeding experiment covered different doses of feed, raw and heat-treated soy, groups fed balanced (green algae + soy) or unbalanced (soy only) diets. Feeding and measurements of fitness parameters survival and number of offspring (fecundity) was done on a daily basis for the 42-day experiments. At regular intervals all animals were photographed for subsequent measuring of carapace length. For further details on experimental conditions and statistical analyses, see (Cuhra et al. 2014).

Table 1. Experimental treatments, number of experimental animals and feed dosage $(\mathrm{OC}=$ biomass measured as organic carbon, soy = soybean meal, algae = algae feed, Org. , Conv. and GM = organic, conventional, and GM soy, respectively).

\begin{tabular}{|c|c|c|c|c|c|}
\hline \multirow[t]{2}{*}{ Treatment } & \multirow[t]{2}{*}{ Diet type $\left(\mathrm{mg} \mathrm{d}^{-1} \mathrm{OC}\right)$} & \multicolumn{4}{|c|}{ Number of experimental animals and soybean-meal type } \\
\hline & & Org. & Conv. & GM & Control \\
\hline A & 0.1 raw soy +0.2 algae & 15 & 15 & 15 & \\
\hline B & 0.1 heated soy +0.2 algae & 15 & 15 & 15 & \\
\hline $\mathrm{C}$ & 0.1 raw soy & 15 & 15 & 15 & \\
\hline $\mathrm{D}$ & 0.2 raw soy & 15 & 15 & 15 & \\
\hline E & 0.1 heated soy & 15 & 15 & 15 & \\
\hline $\mathrm{F}$ & 0.2 heated soy & 15 & 15 & 15 & \\
\hline G & 0.2 algae & & & & 30 \\
\hline
\end{tabular}




\section{Results}

\section{Glyphosate and AMPA residues in the soybeans}

All individual samples of GM-soy contained residues of both glyphosate and AMPA. In contrast, no sample from the conventional or the organic soybeans showed any residues of these compounds (Figure 1). In the GM-soy samples, the concentration of AMPA (mean concentration $=5.74 \mathrm{mg} / \mathrm{kg}$ ) was on average nearly twice as high as glyphosate $(3.26 \mathrm{mg} / \mathrm{kg})$. The mean concentration of glyphosate + AMPA in the GM soybeans was $9.0 \mathrm{mg} / \mathrm{kg}$.

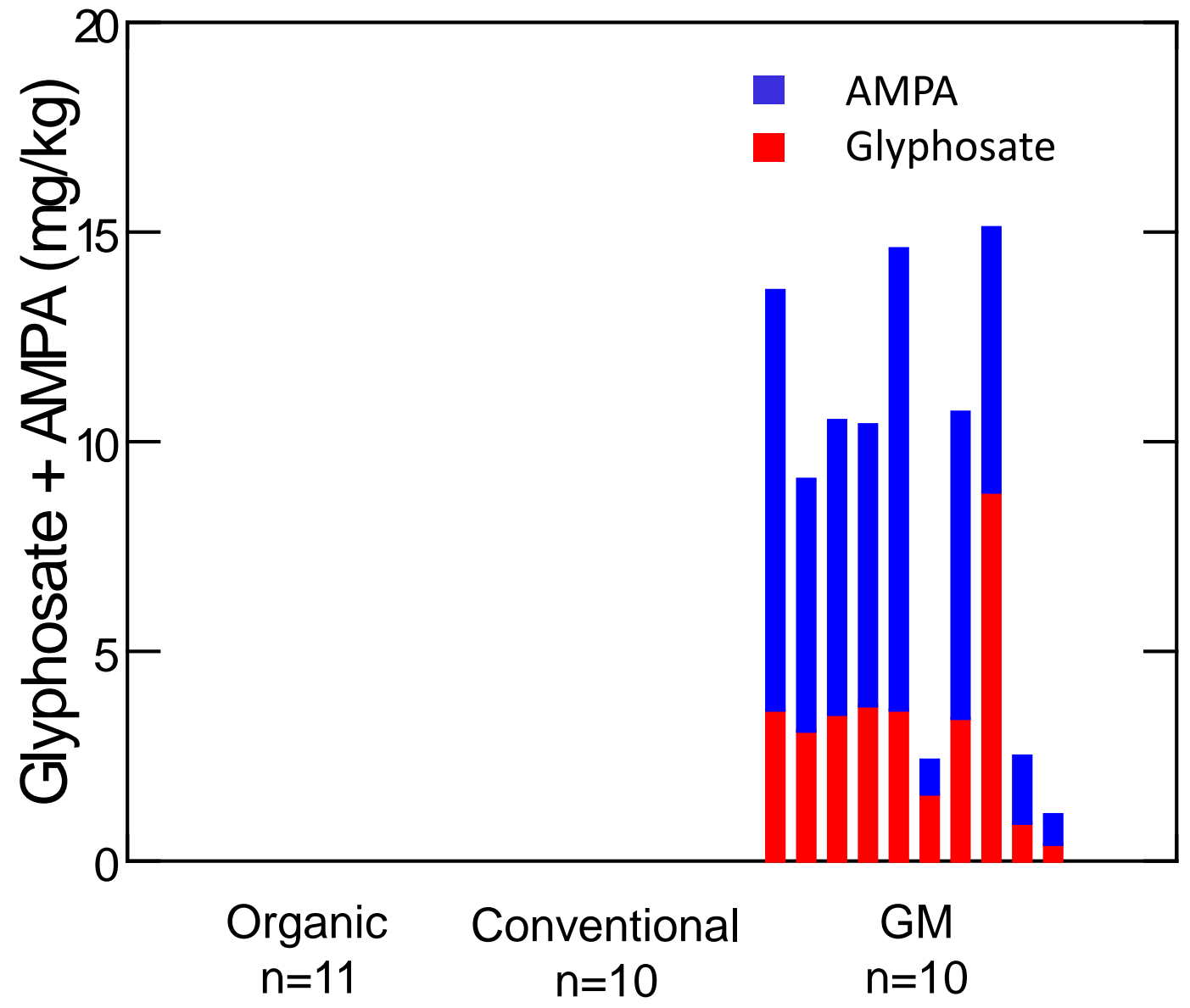

Figure 1. Residues of glyphosate and AMPA in individual soybean samples ( $\mathrm{n}=31)$. For conventional and organic soybeans all measurements were below the detection limit of 0.1 mg/kg. (Reproduced from Bøhn et al. 2014, with permission.) 
The soy samples were also tested for other pesticides, but only trace-levels, not considered relevant were found, see (Bøhn, Cuhra, Traavik, Sanden, Fagan, and Primicerio 2014) for further details.

Main constituents of the soy - individual samples

The organic soybeans differed in nutrient composition compared to the conventional and GM soybeans in several variables (Table 2). The organic samples contained significantly more total protein as compared to both GM-soy and conventional soy ( $<<0.01$, ANOVA, Tukey correction), which was also reflected in a higher content of the essential amino acids (IAAs). The content of 18:2n-6, and the sum of saturated fats were significantly lower in the organic soybean material. There were no significant differences in the 18:1n-9 (monounsaturated) or the 18:3n-3 (Omega 3) fatty acids between the three groups.

The contents of zinc and barium were significantly higher in the organic samples compared to conventional and GM samples, while the content of selenium was lower. Other differences were relatively small (Table 2). There was a significant positive correlation between AMPA residue levels and iron ( $\mathrm{p}=0.028$, linear regression) and AMPA residue levels and 18:2n-6 content in the GM soybeans ( $p=0.016$, linear regression). 
Table 2. Composition of nutrients and elements in the different soybean types. Results are given as mean $\pm S D$, based on measurement on individual samples. Significant differences $(p<0.05)$ between means are indicated by different letters. (Reproduced from Bøhn et al. 2014, with permission.)

\begin{tabular}{|c|c|c|c|c|c|c|c|}
\hline & GM & $\mathrm{SD}$ & Conv. & SD & Organic & SD & Anova \\
\hline \multicolumn{8}{|l|}{ Proximate composition } \\
\hline Dry matter (\%) & 89.4 & 1.4 & 88.1 & 2.0 & 88.2 & 2.6 & ns \\
\hline Protein (\%) & $34.6^{b}$ & 1.3 & $34.3 \mathrm{~b}$ & 1.5 & $36.3^{a}$ & 1.1 & $\mathrm{p}=0.003$ \\
\hline Fat $(\%)$ & 19.0 & 0.8 & 19.1 & 1.3 & 18.3 & 0.9 & ns \\
\hline Ash (\%) & $4.6 \mathrm{ab}$ & 0.2 & $4.5 \mathrm{~b}$ & 0.2 & 4.7 a & 0.2 & $\mathrm{p}=0.005$ \\
\hline \multicolumn{8}{|l|}{ Amino acids (mg/g) } \\
\hline Methionine & 4.2 & 0.3 & 4.0 & 0.3 & 4.0 & 0.4 & ns \\
\hline Lysine & $22.1^{b}$ & 1.5 & $22.2^{b}$ & 1.3 & $24.2^{\mathrm{a}}$ & 0.9 & $\mathrm{p}=0.002$ \\
\hline Histidine & 8.9 & 0.3 & 8.9 & 0.4 & 9.0 & 0.6 & ns \\
\hline Isoleucine & 15.2 & 0.7 & 15.0 & 0.7 & 15.6 & 0.5 & ns \\
\hline Leucine & $26.3^{\mathrm{ab}}$ & 0.9 & $26.2 \mathrm{~b}$ & 1.1 & $27.4^{\mathrm{a}}$ & 1.0 & $\mathrm{p}=0.02$ \\
\hline Phenylalanine & 18.0 & 0.6 & 17.7 & 0.7 & 18.0 & 1.2 & ns \\
\hline Threonine & 13.8 & 0.4 & 13.8 & 0.5 & 14.3 & 0.6 & ns \\
\hline Valine & 15.9 & 0.7 & 15.7 & 0.7 & 16.3 & 0.6 & ns \\
\hline Arginine & $24.0 \mathrm{ab}$ & 0.9 & $23.4^{\mathrm{b}}$ & 1.1 & $24.9^{\text {a }}$ & 1.8 & $\mathrm{p}=0.04$ \\
\hline Sum of EAAs ${ }^{1}$ & 142.3 & 5.4 & 140.8 & 5.2 & 147.1 & 5.8 & $\mathrm{p}=0.037$ \\
\hline \multicolumn{8}{|l|}{ Vitamins (mg/kg) } \\
\hline Vitamin B6 & 15.7 & 1.5 & 14.9 & 1.2 & 14.9 & 1.4 & ns \\
\hline \multicolumn{8}{|l|}{ Fatty acids (mg/g) } \\
\hline 16:0 (palmitic acid) & $22.6^{a}$ & 1.2 & $21.1 \mathrm{ab}$ & 1.1 & $21.0^{b}$ & 1.9 & $\mathrm{p}=0.046$ \\
\hline Sum Saturated & 33.0 a & 1.4 & $31.0 \mathrm{ab}$ & 1.6 & 29.7 b & 2.3 & $\mathrm{p}=0.001$ \\
\hline $18: 1 n-9$ (oleic acid) & 41.1 & 3.0 & 38.5 & 2.9 & 38.5 & 4.3 & ns \\
\hline Sum Monounsaturated & 44.4 & 3.2 & 41.5 & 3.1 & 41.5 & 4.5 & ns \\
\hline 18:2n-6 (linoleic acid) & $115.7 \mathrm{ab}$ & 5.2 & $117.8 \mathrm{a}$ & 5.8 & $\begin{array}{l}108.4 \\
\text { b }\end{array}$ & 9.3 & $\mathrm{p}=0.01$ \\
\hline 18:3n-3 (linolenic acid) & 19.1 & 4.4 & 19.6 & 0.8 & 18.0 & 1.6 & ns \\
\hline \multicolumn{8}{|l|}{ Elements mg/kg } \\
\hline Barium (Ba) & $6.4 \mathrm{~b}$ & 2.2 & $6.2 \mathrm{~b}$ & 1.7 & $11.0^{\mathrm{a}}$ & 3.3 & $\mathrm{p}=0.0005$ \\
\hline Copper $(\mathrm{Cu})$ & 10.4 & 1.1 & 10.8 & 1.1 & 11.3 & 1.7 & ns \\
\hline Iron $(\mathrm{Fe})$ & 86.8 & 7.2 & 84.4 & 8.7 & 84.7 & 11.3 & ns \\
\hline Manganese (Mn) & 24.1 & 2.8 & 22.8 & 1.7 & 24.5 & 2.3 & ns \\
\hline Molybdenum (Mo) & 1.9 & 1.0 & 4.5 & 4.0 & 2.1 & 1.1 & ns \\
\hline Selenium (Se) & 0.7 a & 0.1 & $0.8^{a}$ & 0.2 & $0.2 \mathrm{~b}$ & 0.2 & $\mathrm{p}=0.0003$ \\
\hline Zinc (Zn) & $30.4 \mathrm{~b}$ & 2.4 & $31.7 \mathrm{~b}$ & 2.8 & 37.0 a & 3.4 & $\mathrm{p}=0.0002$ \\
\hline
\end{tabular}

${ }^{1}$ EAAs essential amino acids (except tryptophan). 


\section{Discriminant analysis}

Soy from the three different categories, GM, conventional and organic, could be well separated (Figure 2). The first axis of variation mainly separated organic samples from both the GM and conventional, while the second axis differentiated the GM from conventional.

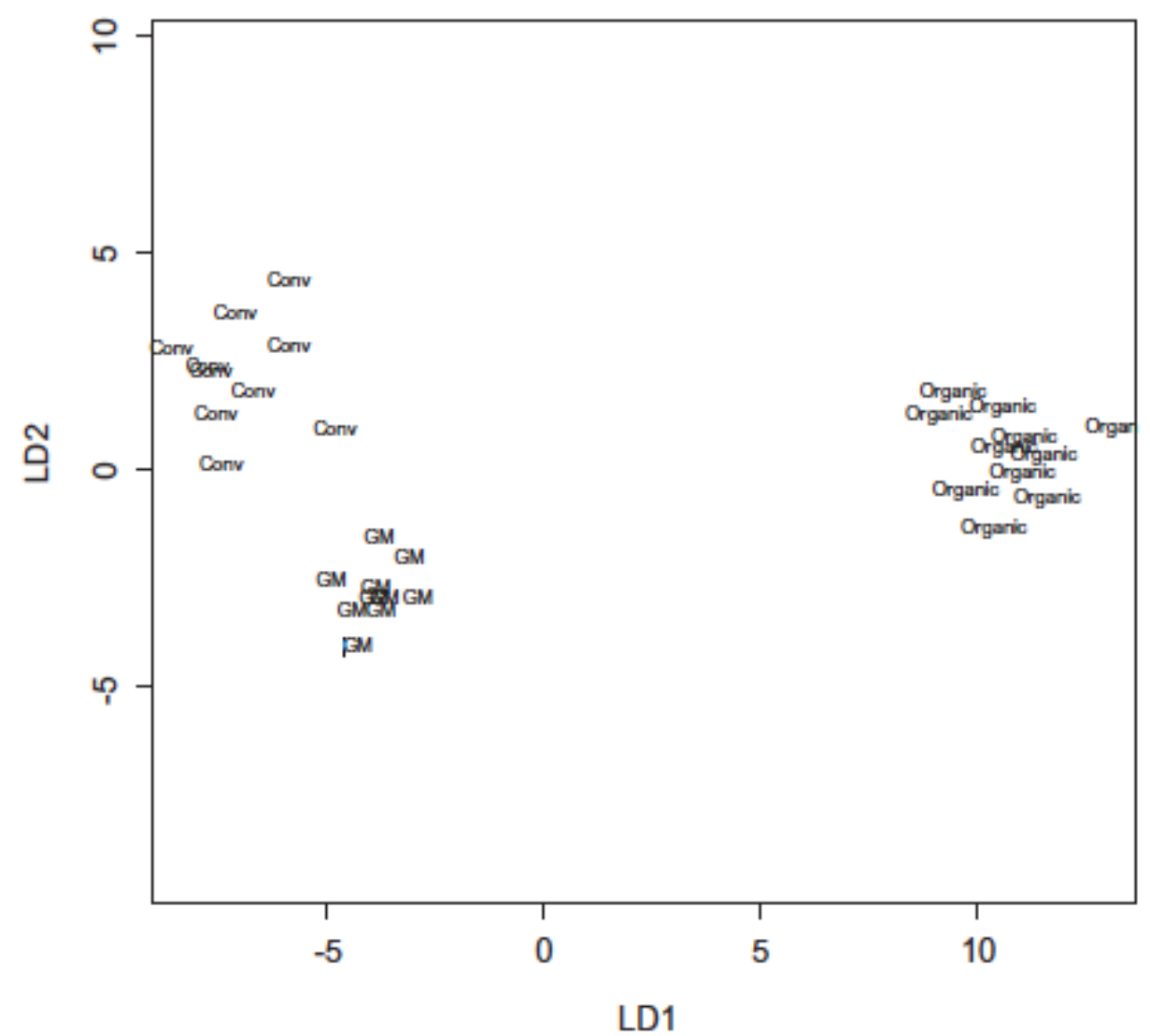

Figure 2. Discriminant analysis for GM, conventional and organic soy samples based on 35 variables. Data were standardised (mean $=0$ and $S D=1)$. Glyphosate/AMPA residues were not included (would have separated the GM soy from non-GM soy). (Reproduced from Bøhn et al. 2014, with permission.) 


\section{Life-time feeding studies in D. magna with the different soy types}

\section{Survival}

Animals fed green algae and soy in combination showed minor differences in survival between the different soy types (data not shown).

Animals fed raw GM soy only (without green algae) showed reduced survival, both with low and with high doses, compared to animals fed conventional and organic soy. The life expectancy of GM-fed D. magna was 15-18 days, much lower than for animals fed conventional soy (24-32 days) and organic soy (24-36 days) (Figure 3). When the soy feed was heat-treated the results were mixed, with smaller and less systematic differences between the groups (Figure 3).

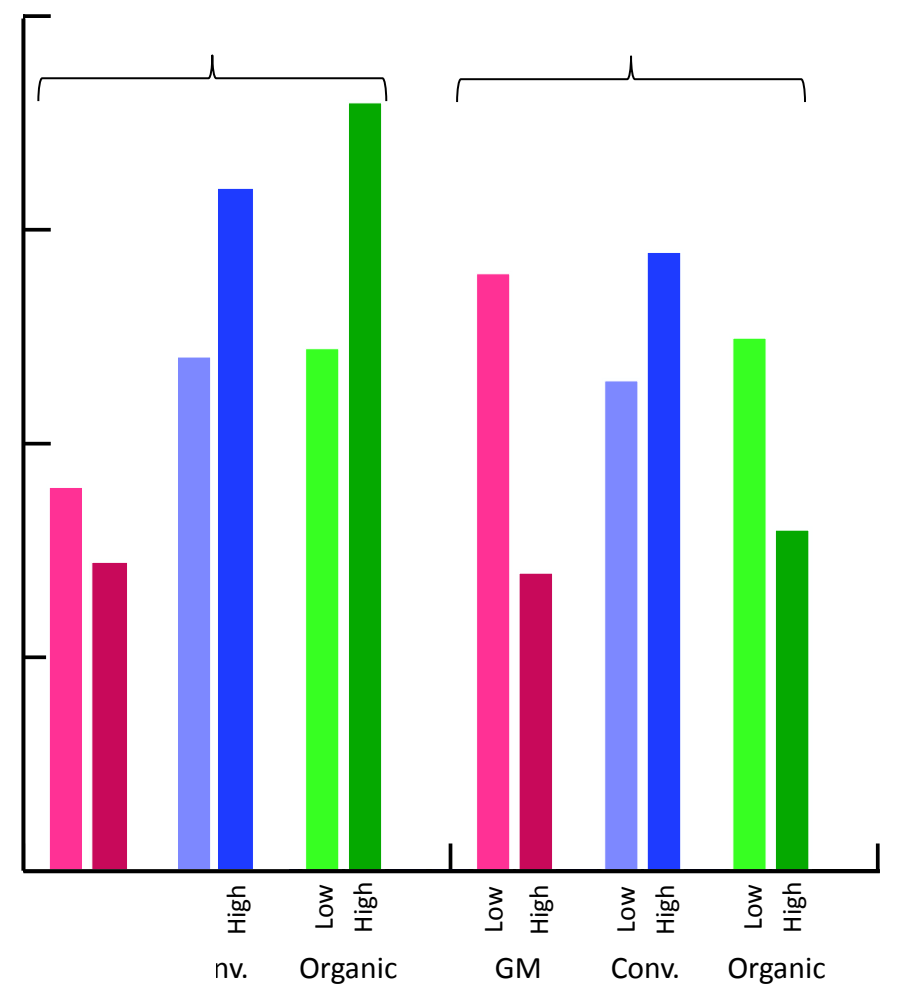

Figure 3. Life expectancy of animals fed different soy treatments, calculated as median expected survival based on Cox regression models with survival over time (survreg model in R software). 
Reproductive output - nutritionally balanced diets (green algae and soy) Animals fed green algae and low dose soy in combination performed excellently when the soy was heat treated, but less well when the soy was raw (Figure 4). The reproductive output of animals fed organic raw soy was roughly three times the reproductive output of animals fed GM and conventional soybeans (Figure 4). In contrast, significant differences were not observed for groups fed heat-treated soy.

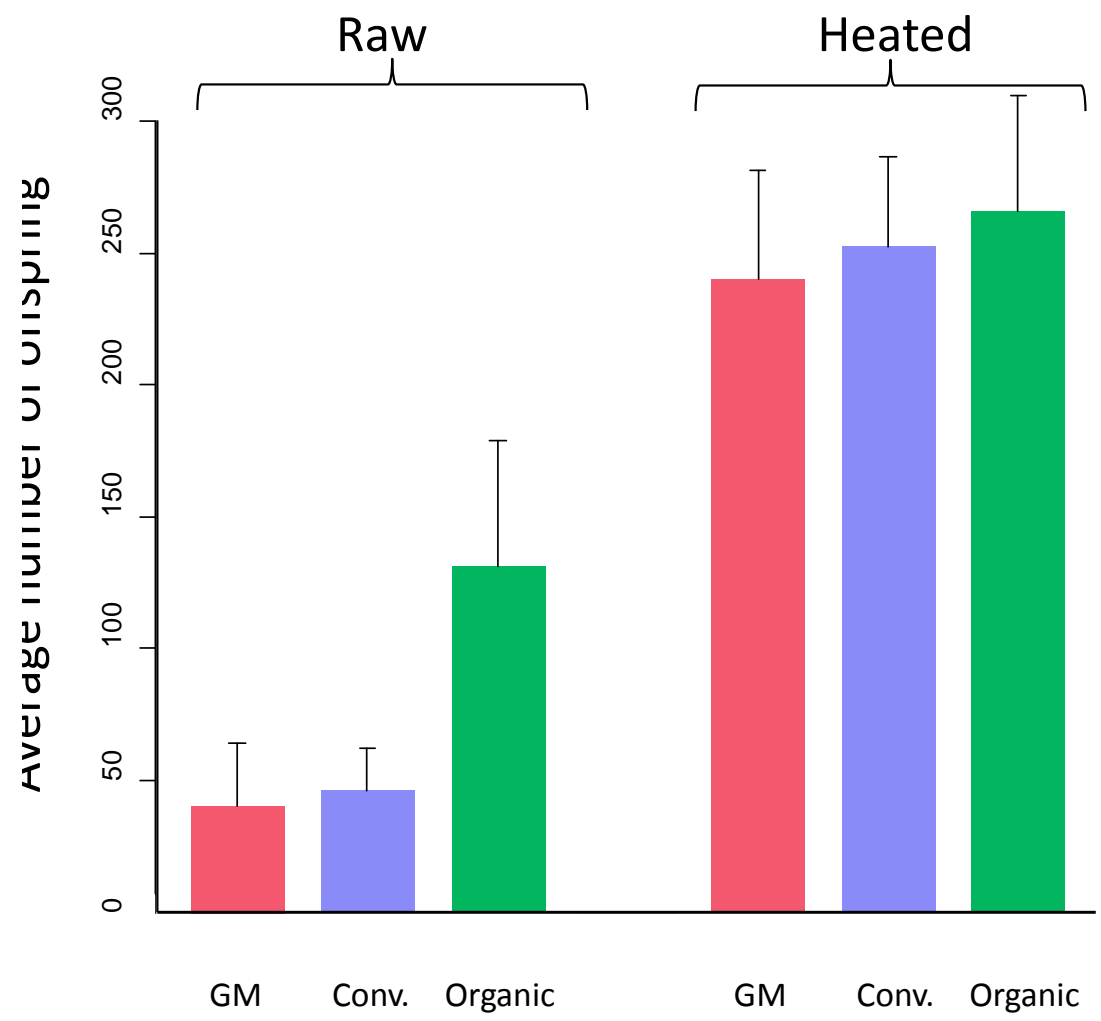

Figure 4. Life-time reproductive output (fecundity) with $95 \%$ confidence intervals in D. magna fed a low dose of GM, conventional or organic soybeans raw or heattreated, in addition to green algae. 
Reproductive output - nutritionally incomplete diets (soy only)

D. magna fed low doses of raw soy produced a limited number of offspring.

However, the lifetime fecundity of animals fed organic soybeans was more than double compared to animals fed conventional and GM soybeans, with confidence limit not overlapping the mean of those groups (Figure 5). Although high doses of organic soy led to higher fecundity, the variability was also very high. The results were less systematic when animals were fed heat-treated soy. The GM soy performed in general inferior to conventional and organic soybeans (Figure 5).

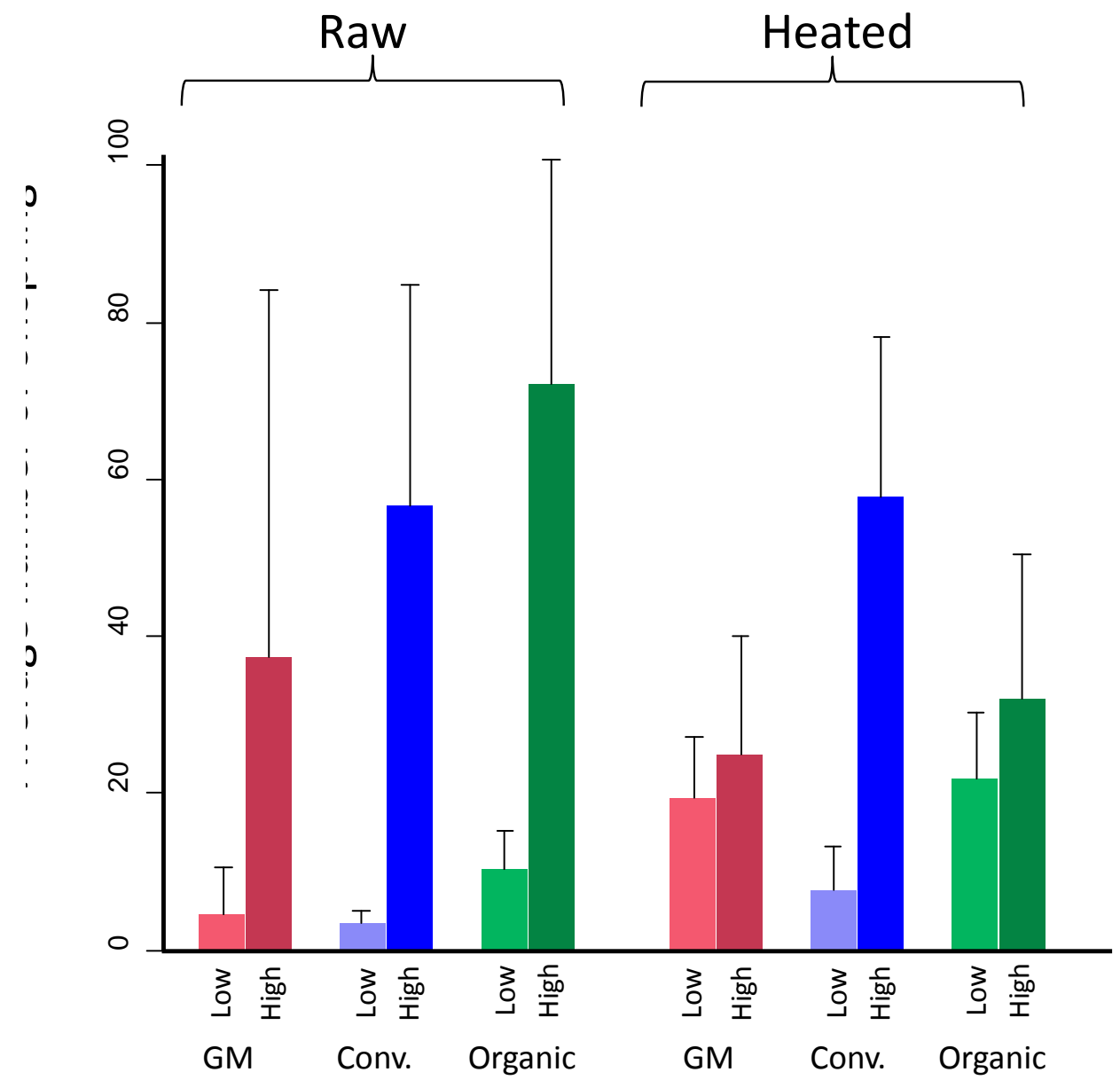

Figure 5. Lifetime reproductive output (fecundity) with $95 \%$ confidence intervals in D. magna fed raw or heat-treated GM, conventional or organic soybeans at low or high doses (no algal supplement). 


\section{Discussion}

The presented studies demonstrate that the products of the three agricultural systems investigated differ significantly in composition. Furthermore, since the feed produced in these three systems lead to significant differences in life expectancy and fecundity of D. magna, these differences are biologically relevant. Organic soy was differentiated from GM and conventional soy based on the levels of several individual analytes, while, discriminant analysis, examining 35 different analytes (excluding glyphosate and AMPA) successfully differentiated GM and conventional soy analytically (Figure 2). The biological relevance of these distinctions is supported by the result that the life expectancy of $D$. magna fed GM soy differs significantly from that of D. magna fed conventional or organic soy (Figure 3 ) and the result that the reproductive output was superior in D. magna fed organic soy, intermediate in animals fed conventional soy and inferior i animals fed GM soy (Figure 4 and Figure 5).

The tested 'ready-to-market' soybeans, grown in three different commercial production systems, present new insights into the chemical and biological properties of the products of commercial agriculture. The test samples included a range of soy varieties, produced on different farms, but with similar soils and grown in a relatively well-defined geographical region, in the same climactic zone and season. This is quite a different approach than assessment of products from test-plots grown under tightly controlled, idealized conditions. In contrast, the materials analyzed in this study resembles those encountered by a consumer shopping in a retail store (Chhabra et al. 2013), or by a food or feed manufacturer purchasing soy from the commodity market. Although less controlled, the study provides a wider perspective on the marketplace by analyzing, both chemically and biologically, products representative of the products of the three most common systems of agricultural in operation today.

\section{Residues of pesticides in the soy}

The most striking compositional difference between the Roundup Ready GM soybeans and conventional and organic soybeans was the presence only in Roundup Ready GM-soybeans of glyphosate and AMPA at concentrations of 0.4 - 8.8 and 0.7 $10 \mathrm{mg} / \mathrm{kg}$, respectively. This is empirical evidence supporting what has been 
considered as a working hypothesis for herbicide tolerant crops, namely that "there is a theoretical possibility that also the level of residues of the herbicide and its metabolites may have increased", (Kleter et al. 2011) is actually happening. Using the FAO definition of pesticide residues, total glyphosate residues should be calculated as the sum of gly + 1.5x AMPA (FAO 2005). Using this formula, the mean level of 'glyphosate equivalents' is even higher: $11.9 \mathrm{mg} / \mathrm{kg}$ for the GM soybeans (max. 20.1 $\mathrm{mg} / \mathrm{kg})$.

Monsanto has claimed that residues of glyphosate in GM soy are lower than in conventional soy, where glyphosate residues have been measured up to $17 \mathrm{mg} / \mathrm{kg}$ (FAO 2005; Monsanto 1999). These very high levels could only have been the result of the practice of desiccation in which Roundup is used to kill and desiccate conventional soy plants to bring the crop to a uniform degree of "maturity", to facilitate harvesting. Desiccation is used at times in the US, Canada and Europe, and can add substantially to the residue levels of glyphosate and AMPA, as shown in field pea, barley and flax seed (Cessna et al. 2002). However, this is clearly not a common practice in Iowa, based on the findings presented in this chapter. Therefore desiccated soybeans should not be considered a benchmark for glyphosate levels in conventional soy.

Previous information have indicated a maximum glyphosate level up to $5.6 \mathrm{mg} / \mathrm{kg}$ in GM-soy and this was claimed to represent "...extreme levels, and far higher than those typically found" (Monsanto 1999). Seven out of the 10 GM-soy samples we tested surpassed this "extreme level" of glyphosate + AMPA residues, reflecting the increased use of glyphosate on Roundup Ready soybeans in the US (Benbrook 2012). This has taken place in response to emergence of glyphosate resistant weeds and is contributing to selection of glyphosate-tolerant weeds (Shaner et al. 2012).

The concept of 'substantial equivalence' (i.e. close nutritional and chemical similarity between a genetically modified (GM) crop and a non-GM counterpart) has been used to claim that GM crops are substantially equivalent to, and therefore as safe and nutritious as, currently consumed plant-derived foods (Aumaitre 2002; Konig et al. 2004). However, we argue that compositional studies that have overlooked (not 
measured) pesticide residues contain serious shortcomings. Chemical residues, if present, are important because i) they are clearly part of a plant's composition, and ii) they may add toxic properties to the final plant product either by itself or by affecting the plant metabolism. This is particularly relevant for herbicide-tolerant varieties.

\section{Increases in Maximum Residue Levels (MRL) of glyphosate in food and feed}

To accommodate these increases in use of glyphosate, authorities in several countries have raised the maximum residue level (MRL) allowed for glyphosate on soybeans by 50 to 200 percent. Europe and the US have increased the MRL to $20 \mathrm{mg} / \mathrm{kg}$, while Brazil has increased the MRL to $10 \mathrm{mg} / \mathrm{kg}$ (Agencia Nacional de Vigilancia Sanitaria 2003). MRLs appear to have been adjusted, not based on new evidence indicating glyphosate toxicity was less than previously understood, but to avoid conflicts in the marketplace increases in glyphosate residues resulting from increased use in GM soy production.

\section{Toxicity and health relevance of pesticide/glyphosate residues}

The importance of pesticide residues is recognized in feeding studies assessing risk of GMOs. For glyphosate-tolerant GM soybeans, the European Food Safety Authority has argued that (i) the levels of glyphosate should be analyzed as part of the testing, and (ii) both glyphosate-treated and untreated soybeans should be used in order to separate effects of the plant and the herbicide (van Haver et al. 2008).

However, in early studies of the composition of Roundup-Ready GM soy (Padgette et al. 1996), the researchers did not spray the tested plants with Roundup or glyphosate (Millstone et al. 1999). This shortcoming was corrected in some studies, which claimed Roundup Ready soybeans to be substantially equivalent to non-GM soybeans (Harrigan et al. 2007; McCann et al. 2005). A similar shortcoming is found in feeding studies. Viljoen showed that out of 16 feeding studies testing the quality of herbicide tolerant GM crop products, 13 did not spray the GM plants (Viljoen 2013).

It is full, formulated Roundup herbicide, not glyphosate in isolation, which is used in the field, and, thus, it is relevant to consider, not only the active ingredient glyphosate and its breakdown product AMPA, but also the other compounds present in the 
herbicide formulation. Roundup herbicide formulations typically contain surfactants (termed adjuvants) to facilitate penetration of glyphosate into the plant tissue. Polyoxyethylene amine (POEA) and polyethoxylated tallowamine (POE-15) are commonly used surfactants in Roundup formulations, and have been shown to contribute significantly to the toxicity of Roundup formulations (Benachour and Seralini 2009; Mesnage et al. 2012; Moore et al. 2012). However, glyphosate alone has also been shown to interfere with molecular mechanisms that regulate early development in frogs and chicken, with deformities of embryos as a consequence and the retinoic acid signaling pathway as the affected mediator (Paganelli et al. 2010).

In human cells, Roundup may induce endocrine disturbances at concentrations far below the MRLs cited by authorities in the EU and the US (Benachour and Seralini 2009; Clair et al. 2012; Gasnier et al. 2009). A life-cycle feeding study in rats reported health damaging effects and found significantly altered blood parameters in animals that were fed Roundup Ready GM maize or were given extremely small amounts of Roundup in the drinking water (Seralini et al. 2012). The authors emphasized the role of pesticide residues in edible herbicide tolerant GM plants and argued that these must be evaluated very carefully to accurately assess potential toxic effects. This study has been criticized for its methods, analysis and reporting by (EFSA 2012), which initially rejected the central conclusion of this study, that long term (life-time) toxicity and carcinogenicity studies are needed. However, as well as regulatory authorities from multiple EU states are now acknowledging that this study flagged up the need for long term studies (EU 2012).

Our recent study in D. magna demonstrated that chronic exposure to glyphosate or fully formulation Roundup herbicide resulted in negative effects on reproductive aberrations like reduced fecundity and increased abortion rate at environmental concentrations of 0.45-1.35 mg/liter (active ingredient), well below accepted environmental tolerance limits set in the US (Cuhra, Traavik, and Bøhn 2013). Reduced body size of juveniles was even observed at a Roundup level of 0.05 $\mathrm{mg} /$ liter. These results are strikingly different from data reported by a study funded by the European Commission which indicated a NOEC (No Observed Effect Concentration) in D. magna of $455 \mathrm{mg} / \mathrm{l}$ and $30 \mathrm{mg} / \mathrm{l}$ for glyphosate-IPA and glyphosate acid, respectively (EC 2002). 
The toxicity and health relevance of glyphosate and Roundup have been debated widely. Other studies claim that glyphosate is not linked to developmental or reproductive effects in animals and humans, but that surfactants may cause some toxic effects (Williams et al. 2012; Williams et al. 2000). This controversy has been reviewed in depth by (Antoniou et al. 2012), reaching the conclusion that the weight of evidence indicates that glyphosate itself is a teratogen and that adjuvants commonly used in conjunction with glyphosate amplify this effect.

\section{Nutritional components}

Several factors determine soybean nutritional quality; protein content, mineral content, fatty acid (FA) composition and trace nutrient content are all of central importance. Our results clearly show that the different agricultural practices studied affect soybean nutritional quality. The organic production system produced soybeans that contained statistically higher levels of protein, ash, lysine, leucine, arginine, barium and zinc than those found in conventional and GM soybeans. All of these improve the nutritional content of soybeans. Interestingly, the organic soybeans had significantly lower levels of linoleic acid LA (18:2n-6) and palmitic acid PA (16:0). Although LA is an essential fatty acid, a high and unbalanced intake (high omega 6 and low omega 3 ) is emerging as a risk factor for developing obesity (Muhlhausler and Ailhaud 2013). Thus the reduced levels of PA should enhance the healthfulness of organic soybeans even further. Likewise reduction of LA in organic soybeans enhances healthfulness, since it is a saturated fatty acid. In a recent scientific opinion (EFSA 2010) it was concluded that saturated fatty acid intake should be as low as possible within the context of nutritionally adequate diets.

Comparisons between organic and conventional agriculture have not reached consistent conclusions on nutritional quality, but a review based on 223 compositional studies of nutrients and contaminants found that organic foods have significantly lower levels of pesticide residues (Smith-Spangler et al. 2012), which is consistent with our findings. We found that glyphosate which was present at high levels in GM soybeans, was undetectable in organic and conventional soybeans. 
A recent feeding study that compared organic and conventional food products concluded that organic foods may be more nutritionally balanced than conventional foods, or that they contain higher levels of nutrients, since the fruit fly Drosophila melanogaster lived longer and produced more offspring when fed organic soybeans (or potatoes, raisins, bananas) as compared to conventional produce (Chhabra, Kolli, and Bauer 2013). Organic crops may be more variable in phenotype than industrially produced plant products, but are in general richer in some nutritionally important elements, in antioxidant phytochemicals and lower in pesticide residues (Crinnion 2010). Another recently published meta-analysis reported that organic crops, on average, have higher concentrations of antioxidants and certain other vitamins and micronutrients, lower concentrations of $\mathrm{Cd}$ and a lower incidence of pesticide residues than the non-organic comparators across regions and production seasons (Baranski et al. 2014). Our data support the conclusions of these two reviews. Organic crops have also been reported to contain, on average, four-fold higher content of selenium (Smith 1993). However our data indicates that this is not the case for soybeans, where the selenium content was significantly lower in organic soybeans compared to GM and conventional soybeans.

The effects of genetic modification on nutritional value have not been studied extensively. Some researchers have found differences. For instance, conventional soybeans were reported to have superior nutrient and dry matter composition compared to glyphosate-treated GM-soybeans (Zobiole et al. 2012). However, one review has been published on this topic, reporting conflicting results, with most studies indicating that mineral nutrition is not affected by the glyphosate tolerance trait or application of glyphosate (Duke et al. 2012).

\section{Conclusion}

Data on herbicide accumulation in herbicide-tolerant GM-crops are generally sparse. We found that Roundup Ready GM-soy has high levels of glyphosate and AMPA, and also that different agricultural practices may result in markedly different nutritional composition of soybeans, with organic soybeans having an improved 
nutritional profile than conventional and GM soybeans. This was supported by the feeding studies, in particular for raw soybeans. We demonstrate that pesticide residues have biological significance by inducing negative effects on lifespan and fecundity of test-animals. Thus such residues should be routinely monitored in herbicide-tolerant GM-crops. Roundup Ready soy has been commercially produced for nearly two decades and we find it worrying that the questions concerning glyphosate residues have yet to be addressed systematically by regulatory authorities. We argue that such monitoring should have been a part of the compositional analyses of herbicide tolerant GM plants from the beginning of commercial cultivation. Lack of data on pesticide residues in major crop plants is a serious gap of knowledge with potential consequences for human and animal health. We therefore recommend (i) systematic monitoring and testing of crop material from the market; (ii) testing for possible biological effects of chemical residues in long-term feeding studies; (iii) inclusion of pesticide residue measurements and safety testing as part of the standard risk assessment research required by regulators and (iv) further research on the indirect ecological effects of herbicides and pesticides, i.e. on nutrient uptake and plant composition as well as on ecological interactions in terrestrial, soil and aquatic communities.

\section{Acknowledgements}

We thank the Research Council of Norway for funding under the program “ENVIRONMENT2015” (Project number 184107).

\section{References:}

Agencia Nacional de Vigilancia Sanitaria. 2003. Consulta Publica No 84, D.O.U de 04/11.

American Soy Association. 2013. Soystats.-----. 2015. http://www.nass.usda.gov/Statistics_by_Subject/index.php?sector=CROPS.

Antoniou, M., C. Robinson, and J. Fagan. 2012. GMO Myths and Trouths - An evidence-based examination of the claims made for the safety and efficacy of genetically modified crops., 1-123. London: Earth Open Source.

Asselman, J., S. P. Glaholt, Z. Smith, G. Smagghe, C. R. Janssen, J. K. Colbourne, J. R. Shaw, and K. A. C. De Schamphelaere. 2012. Functional characterization 
of four metallothionein genes in Daphnia pulex exposed to environmental stressors. Aquatic Toxicology 110: 54-65.

Aumaitre, L. A. 2002. New feeds from genetically modified plants: substantial equivalence, nutritional equivalence and safety for animals and animal products. Productions Animales 15 (2): 97-108.

Baranski, M., D. Ürednicka-Tober, N. Volakakis, C. Seal, R. Sanderson, G. B. Stewart, C. Benbrook, B. Biavati, E. Markellou, and C. Giotis. 2014. Higher antioxidant and lower cadmium concentrations and lower incidence of pesticide residues in organically grown crops: a systematic literature review and meta-analyses. British Journal of Nutrition 112 (05): 794-811.

Beckie, Hugh J. 2014. Herbicide Resistance in Weeds and Crops: Challenges and Opportunities. In Recent Advances in Weed Management, 347-364. Springer.

Benachour, N., and G. E. Seralini. 2009. Glyphosate Formulations Induce Apoptosis and Necrosis in Human Umbilical, Embryonic, and Placental Cells. Chemical Research in Toxicology 22 (1): 97-105.

Benbrook, C. M. 2012. Impacts of genetically engineered crops on pesticide use in the U.S. - the first sixteen years. Environmental Science Europe 24:24.

Bøhn, T., M. Cuhra, T. Traavik, M. Sanden, J. Fagan, and R. Primicerio. 2014. Compositional differences in soybeans on the market: Glyphosate accumulates in Roundup Ready GM soybeans. Food Chemistry 153: 207-215.

Bøhn, T., R. Primicerio, D. O. Hessen, and T. Traavik. 2008. Reduced fitness of Daphnia magna fed a Bt-transgenic maize variety. Archives of Environmental Contamination and Toxicology 55 (4): 584-592.

Bøhn, T., T. Traavik, and R. Primicerio. 2010. Demographic responses of Daphnia magna fed transgenic Bt-maize. Ecotoxicology DOI 10.1007/s10646-0090427-x. (Open Access). (19): 419-430.

Cessna, A. J., A. L. Darwent, L. Townley-Smith, K. N. Harker, and K. J. Kirkland. 2002. Residues of glyphosate and its metabolite AMPA in field pea, barley and flax seed following preharvest applications. Canadian Journal of Plant Science 82 (2): 485-489.

Chhabra, R., S. Kolli, and J. H. Bauer. 2013. Organically Grown Food Provides Health Benefits to Drosophila melanogaster. Plos One 8 (1): 1-8.

Clair, E., R. Mesnage, C. Travert, and G. E. Seralini. 2012. A glyphosate-based herbicide induces necrosis and apoptosis in mature rat testicular cells in vitro, and testosterone decrease at lower levels. Toxicology in Vitro 26 (2): 269-279.

Colbourne, J. K., M. E. Pfrender, D. Gilbert, W. K. Thomas, A. Tucker, T. H. Oakley, S. Tokishita, A. Aerts, G. J. Arnold, M. K. Basu, D. J. Bauer, C. E. Caceres, L. Carmel, C. Casola, J. H. Choi, J. C. Detter, Q. F. Dong, S. Dusheyko, B. D. Eads, T. Frohlich, K. A. Geiler-Samerotte, D. Gerlach, P. Hatcher, S. Jogdeo, J. Krijgsveld, E. V. Kriventseva, D. Kultz, C. Laforsch, E. Lindquist, J. Lopez, 
J. R. Manak, J. Muller, J. Pangilinan, R. P. Patwardhan, S. Pitluck, E. J. Pritham, A. Rechtsteiner, M. Rho, I. B. Rogozin, O. Sakarya, A. Salamov, S. Schaack, H. Shapiro, Y. Shiga, C. Skalitzky, Z. Smith, A. Souvorov, W. Sung, Z. J. Tang, D. Tsuchiya, H. Tu, H. Vos, M. Wang, Y. I. Wolf, H. Yamagata, T. Yamada, Y. Z. Ye, J. R. Shaw, J. Andrews, T. J. Crease, H. X. Tang, S. M. Lucas, H. M. Robertson, P. Bork, E. V. Koonin, E. M. Zdobnov, I. V. Grigoriev, M. Lynch, and J. L. Boore. 2011. The Ecoresponsive Genome of Daphnia pulex. Science 331 (6017): 555-561.

Crinnion, W. J. 2010. Organic Foods Contain Higher Levels of Certain Nutrients, Lower Levels of Pesticides, and May Provide Health Benefits for the Consumer. Alternative Medicine Review 15 (1): 4-12.

Cuhra, M., T. Traavik, and T. Bøhn. 2013. Clone- and age-dependent toxicity of a glyphosate commercial formulation and its active ingredient in Daphnia magna. Ecotoxicology 22 (2): 251-262 (open access). DOI 10.1007/s10646012-1021-1.

-----. 2014. Life cycle fitness differences in Daphnia magna fed Roundup-Ready soybean or conventional soybean or organic soybean. Aquaculture Nutrition (in press).

Duke, S. O., J. Lydon, W. C. Koskinen, T. B. Moorman, R. L. Chaney, and R. Hammerschmidt. 2012. Glyphosate Effects on Plant Mineral Nutrition, Crop Rhizosphere Microbiota, and Plant Disease in Glyphosate-Resistant Crops. Journal of Agricultural and Food Chemistry 60 (42): 10375-10397.

EC. 2002. Review report for the active substance glyphosate., 1-56. European Commission.

EFSA. 2010. Scientific Opinion on the assessment of allergenicity of GM plants and microorganisms and derived food and feed. EFSA Journal 8: 1700.

-----. 2012. Final review of the Séralini et al. (2012a) publication on a 2-year rodent feeding study with glyphosate formulations and GM maize NK603 as published online on 19 September 2012 in Food and Chemical Toxicology. EFSA Journal 10 (11): 2986.

-----. 2014. The 2012 European Union Report on pesticide residues in food. EFSA Journal 12 (12): 3942.

EU. 2012. EU Food Policy.

FAO. 2005. Pesticide residues in food., 1-360. Rome: World Health Organization.

Gasnier, C., C. Dumont, N. Benachour, E. Clair, M. C. Chagnon, and G. E. Seralini. 2009. Glyphosate-based herbicides are toxic and endocrine disruptors in human cell lines. Toxicology 262 (3): 184-191.

Harrigan, G. G., G. Ridley, S. G. Riordan, M. A. Nemeth, R. Sorbet, W. A. Trujillo, M. L. Breeze, and R. W. Schneider. 2007. Chemical composition of glyphosate-tolerant soybean 40-3-2 grown in Europe remains equivalent with 
that of conventional soybean (Glycine max L.). Journal of Agricultural and Food Chemistry 55: 6160-6168.

James, C. 2013. Global Status of Commercialized Biotech/GM Crops: 2013. ISAAA: Ithaca, NY.

Kleter, G. A., J. B. Unsworth, and C. A. Harris. 2011. The impact of altered herbicide residues in transgenic herbicide-resistant crops on standard setting for herbicide residues. Pest Management Science 67 (10): 1193-1210.

Konig, A., A. Cockburn, R. W. R. Crevel, E. Debruyne, R. Grafstroem, U. Hammerling, I. Kimber, I. Knudsen, H. A. Kuiper, A. A. C. M. Peijnenburg, A. H. Penninks, M. Poulsen, M. Schauzu, and J. M. Wal. 2004. Assessment of the safety of foods derived from genetically modified (GM) crops. Food and Chemical Toxicology 42 (7): 1047-1088.

Martin, J. D., C. G. Crawford, and S. J. Larson. 2003. Pesticides in streams. National Water Assessment Program (NAWQA), USA.

McCann, M. C., K. Liu, W. A. Trujillo, and R. C. Dobert. 2005. Glyphosate-tolerant soybeans remain compositionally equivalent to conventional soybeans (Glycine max L.) during three years of field testing. Journal of Agricultural and Food Chemistry 53: 5331-5335.

Mendelson, M, J. Kough, Z. Vaituzis, and K. Matthews. 2003. Are Bt crops safe? Nature Biotechnology 21 (9): 1003-1009.

Mesnage, R., B. Bernay, and G. E. Seralini. 2012. Ethoxylated adjuvants of glyphosate-based herbicides are active principles of human cell toxicity . Toxicology (in press) (http://dx.doi.org/10.1016/j.tox.2012.09.006 ).

Millstone, E., E. Brunner, and S. Mayer. 1999. Beyond 'substantial equivalence'. Nature 401: 525-526.

Monsanto. 1999. Residues in Roundup Ready soya lower than conventional soy.

Moore, L. J., L. Fuentes, J. H. Rodgers, W. W. Bowerman, G. K. Yarrow, W. Y. Chao, and W. C. Bridges. 2012. Relative toxicity of the components of the original formulation of Roundup (R) to five North American anurans. Ecotoxicology and Environmental Safety 78: 128-133.

Muhlhausler, B. S., and G. P. Ailhaud. 2013. Omega-6 polyunsaturated fatty acids and the early origins of obesity. Current Opinion in Endocrinology Diabetes and Obesity 20 (1): 56-61.

Nørgaard, K. B., and N. Cedergreen. 2010. Pesticide cocktails can interact synergistically on aquatic crustaceans. Environmental Science and Pollution Research 17 (4): 957-967.

Orsini, L., E. Decaestecker, L. De Meester, M. E. Pfrender, and J. K. Colbourne. 2011. Genomics in the ecological arena. Biology Letters 7 (1): 2-3. 
Padgette, S. R., N. B. Taylor, D. L. Nida, M. R. Bailey, J. MacDonald, L. R. Holden, and R. L. Fuchs. 1996. The composition of glyphosate-tolerant soybean seeds is equivalent to that of conventional soybeans. Journal of Nutrition 126 (3): 702-716.

Paganelli, A., V. Gnazzo, H. Acosta, S. L. Lopez, and A. E. Carrasco. 2010. Glyphosate-Based Herbicides Produce Teratogenic Effects on Vertebrates by Impairing Retinoic Acid Signaling. Chemical Research in Toxicology 23 (10): 1586-1595.

Pollak, P. 2011. Fine chemicals: the industry and the business. Hoboken: Wiley

Raybould, A., and D. Vlachos. 2011. Non-target organism effects tests on Vip3A and their application to the ecological risk assessment for cultivation of MIR162 maize. Transgenic Research 20 (3): 599-611.

Seralini, G. E., E. Clair, R. Mesnage, S. Gress, N. Defarge, M. Malatesta, D. Hennequin, and J. S. Vendômois. 2012. Long term toxicity of a Roundup herbicide and a Roundup-tolerant genetically modified maize. Food and Chemical Toxicology 50: 4221-4231.

Shaner, D. L., R. B. Lindenmeyer, and M. H. Ostlie. 2012. What have the mechanisms of resistance to glyphosate taught us? Pest Management Science 68 (1): 3-9.

Smith, B. L. 1993. Organic foods vs supermarket foods: Element levels. Journal of Applied Nutrition 45: 35-39.

Smith-Spangler, C., M. L. Brandeau, G. E. Hunter, C. Bavinger, M. Pearson, P. J. Eschbach, V. Sundaram, H. Liu, P. Schirmer, C. Stave, I. Olkin, and D. M. Bravata. 2012. Are Organic Foods Safer or Healthier Than Conventional Alternatives? Annals of Internal Medicine 157 (5): 348-U112.

USDA. 2013. National Agricultural Statistics Service.

USDA-NASS. 2015. National Agricultural Statistics Service.

van Haver, E., G. Alink, S. Barlow, A. Cockburn, G. Flachowsky, I. Knudsen, H. Kuiper, D. P. Massin, G. Pascal, A. Peijnenburg, R. Phipps, A. Poting, M. Poulsen, W. Seinen, H. Spielmann, H. van Loveren, J. M. Wal, and A. Williams. 2008. Safety and nutritional assessment of GM plants and derived food and feed: The role of animal feeding trials. Food and Chemical Toxicology 46: S2-S70.

Viljoen, C. 2013. Letter to the editor. Food and Chemical Toxicology 59: 809-810.

Williams, A. L., R. E. Watson, and J. M. DeSesso. 2012. Developmental and Reproductive Outcomes in Humans and Animals After Glyphosate Exposure: A Critical Analysis. Journal of Toxicology and Environmental Health-Part BCritical Reviews 15 (1): 39-96. 
Williams, G. M., R. Kroes, and I. C. Munro. 2000. Safety evaluation and risk assessment of the herbicide Roundup and its active ingredient, glyphosate, for humans. Regulatory Toxicology and Pharmacology 31 (2): 117-165.

Zobiole, L. H. S., R. S. Oliveira, J. Constantin, A. Oliveira, C. Castro, F. A. Oliveira, R. J. Kremer, A. Moreira, and L. M. Romagnoli. 2012. Nutrient Accumulation in Conventional and Glyphosate-Resistant Soybean under Different Types of Weed Control. Planta Daninha 30 (1): 75-85. 